\title{
Immunohistochemical detection of high-mobility group box 1 correlates with resistance of preoperative chemoradiotherapy for lower rectal cancer: a retrospective study
}

Kumiko Hongo ${ }^{1 *}$, Shinsuke Kazama ${ }^{1}$, Nelson H Tsuno ${ }^{2}$, Soichiro Ishihara', Eiji Sunami ${ }^{1}$, Joji Kitayama ${ }^{1}$ and Toshiaki Watanabe ${ }^{1}$

\begin{abstract}
Background: High-mobility group box 1 (HMGB1) is a nucleoprotein that is related to inflammation. It has been implicated in a variety of biologically important processes, including transcription, DNA repair, differentiation, development, and extracellular signaling. Recently, its important role in the process of tumor invasion, metastasis, and resistance to anti-cancer therapies has been demonstrated. In this study, we aimed to investigate the correlation of HMGB1 expression and resistance of rectal cancer patients to chemoradiotherapy (CRT) prior to curative operation.

Methods: We retrospectively reviewed the data of 75 lower rectal cancer patients without complete pathological response who had received preoperative CRT and had undergone curative resection at the University of Tokyo Hospital between May 2003 and June 2010. HMGB1 expression in surgically resected specimens was evaluated using immunohistochemical detection and specimens were classified into high or low HMGB1 expression groups. Clinicopathologic features, degree of tumor reduction, regression of tumor grade, and patient survival were compared between the groups using non-paired Student's t-tests and Kaplan-Meier analysis.

Results: A total of 52 (69.3\%) patients had high HMGB1 expression, and 23 (30.7\%) had low expression. HMGB1 expression was significantly correlated with histologic type $(P=0.02)$, lymphatic invasion $(P=0.02)$, and venous invasion $(P=0.05)$. Compared to patients with low HMGB1 expression, those with high expression had a poorer response to CRT, in terms of tumor reduction ratio $(42.2$ versus $28.9 \%$, respectively; $P<0.01)$ and post-CRT histological tumor regression grade (56.5 versus $30.8 \%$ grade 2 ; respectively; $P=0.03$ ). However, no significant correlation was found between HMGB1 expression and recurrence-free and overall survival rates.
\end{abstract}

Conclusions: HMGB1 expression may be one of the key factors regulating the response of rectal cancer to preoperative CRT in terms of tumor invasiveness and resistance to therapy.

Keywords: High-mobility group box 1 (HMGB1), Lower rectal cancer, Chemoradiotherapy, Immunohistochemistry

\footnotetext{
* Correspondence: hongokumiko-tky@umin.ac.jp

'Department of Surgical Oncology, Graduate School of Medicine, The University of Tokyo, 7-3-1 Hongo, Bunkyo-ku, Tokyo 113-8655, Japan Full list of author information is available at the end of the article
} 


\section{Background}

High-mobility group box 1 (HMGB1) was first identified as a nuclear chromatin-binding protein that plays significant roles in various biologically important processes, including transcription, DNA repair, differentiation, and development [1]. In addition to its biological functions in the nuclear compartment, HMGB1 functions as an extracellular signaling molecule during inflammation, cell differentiation, cell migration, and metastasis [2-6]. HMGB1 is reported to be actively secreted by inflammatory cells when stimulated by endotoxin, tumor necrosis factor- $\alpha$ (TNF- $\alpha$ ), or interleukin-1 $\beta$ (IL-1 $\beta)$, and is also passively released from necrotic cells $[7,8]$. HMGB1 promotes inflammation by binding to the receptors, such as the receptor for advanced glycation end-products (RAGE), Toll-like receptor (TLR) 2, and TLR-4, which are expressed in a variety of cells including monocytes, macrophages, and endothelial cells [7,9-12]. Through these actions, HMGB1 has been implicated in the pathogenesis of various clinical conditions, including sepsis [13], ischemia-reperfusion [14], meningitis [15], neurodegeneration [16], aging [17], and cancer [5,6,18].

In the pathophysiology of cancer, increased expression of HMGB1 and RAGE is associated with proliferative activity and metastatic potential in many types of tumors, including breast cancer [19], hepatocellular carcinoma [8], melanoma [20], glioma [21,22], prostate cancer [23], gastric cancer [24], and colorectal cancer [25-27]. Increased RAGE-HMGB1 activity induces phosphorylation of extracellular signal-related kinase (ERK) [28], activating GTPases of the Rho family [29]. Thus, it contributes to cancer development through different mechanisms, including angiogenesis [28], cell migration [30], and apoptosis inhibition [24]. Moreover, extracellular reducible HMGB1 has been shown to induce autophagy and promote tumor resistance to alkylators, tubulin disrupting agents, DNA cross-linkers, and DNA intercalators in human pancreatic cancer and colon cancer cell lines [31]. Chemotherapy-induced HMGB1 expression in osteosarcoma cells promotes autophagy to inhibit apoptosis and increase drug resistance [32]. However, HMGB1 has a paradoxical dual effect on tumors [6]. HMGB1 has been shown to stimulate mature dendritic cells to degrade tumor antigen processing through its interaction with TLR-4 [33]. Furthermore, it mediates endogenous TLR-2 activation, resulting in tumor regression [34]. Therefore, the role of HMGB1 in cancer development and progression, as well as its effect on the response to treatment, remains largely unexplored.

Colorectal cancer is a highly invasive and metastatic tumor, and mortality associated with this cancer has increased worldwide recently [35]. Surgical resection and combined modality therapy, including chemotherapy, radiotherapy, and chemoradiotherapy (CRT), are the main therapeutic strategies for the management of rectal cancer. However, the effectiveness of these therapies greatly varies among patients, and those with a weaker response have a worse prognosis. In particular, those who do not respond to neoadjuvant CRT have a poor prognosis [36]. Thus, analysis of the molecular mechanisms underlying the resistance of rectal cancer cells to CRT is essential for the development of novel treatment strategies for the disease. In this study, we performed immunohistochemical analyses to examine HMGB1 expression in surgically resected specimens of rectal cancer after preoperative CRT and investigated its association with clinicopathological features, in an attempt to elucidate the possible association between HMGB1 expression and resistance to CRT.

\section{Methods}

\section{Patients and evaluation of response to} chemoradiotherapy

A total of 82 patients with lower rectal cancer who had received preoperative CRT and undergone curative resection at the University of Tokyo Hospital between May 2003 and June 2010 were enrolled. Patients receiving CRT had cancer in the middle or lower part of the rectum, with tumor invading further than the muscularis propria. CRT consisted of radiotherapy (1.8 Gy $\times 28$ fractions $=50.4$ Gy irradiation) and chemotherapy with a 5 -fluorouracil (FU) prodrug $\left(300 \mathrm{mg} / \mathrm{m}^{2} /\right.$ day $)$ and leucovorin $(75 \mathrm{mg} /$ day), administered orally during the entire course of radiotherapy. We excluded seven patients with complete pathological response after CRT because in this study, we aimed to evaluate the residual cancer cells by immunohistochemical staining. Thus, among the 82 patients, 75 were considered eligible, and HMGB1 expression in surgically resected specimens was evaluated using immunohistochemical analyses. Clinicopathological features were analyzed on the basis of the TNM Classification of Malignant Tumors, Seventh edition, using the International Union Against Cancer (UICC) [37] and World Health Organization (WHO) histological criteria [38]. Post-CRT histological tumor regression was graded according to the seventh edition of the Japanese Guidelines for Clinical and Pathological Studies on Carcinoma of the Colorectum (Table 1) [39]. In this study, both grade 1a and $1 \mathrm{~b}$ were

\begin{tabular}{|c|c|c|}
\hline Grade & & Tumor regression \\
\hline Grade 0 & & Neither necrosis nor regressive change \\
\hline \multirow[t]{2}{*}{ Grade 1} & a & $>2 / 3$ vital residual tumor cells \\
\hline & $\mathrm{b}$ & Approximately $1 / 3$ to $2 / 3$ vital residual tumor cells \\
\hline Grade 2 & & $<1 / 3$ vital residual tumor cells \\
\hline Grade 3 & & No vital residual tumor cells \\
\hline
\end{tabular}


classified together as grade 1 . The reduction ratio was calculated based on the results of barium enema X-ray examination performed before and after CRT. The largest dimension of the tumor, from the same angle, before, and after CRT, was measured, and the post- to pre-CRT ratio was calculated. Patients' consent and approval of the Ethics Committee of the University of Tokyo were obtained for the use of clinical samples for research purposes.

\section{Immunohistochemical evaluation}

Consecutive formalin-fixed paraffin-embedded $4-\mu \mathrm{m}$ sections were used for the immunohistochemical evaluation. After treatment with xylene and ethanol, followed by washing with phosphate-buffered saline (PBS), tumor specimens were subjected to heat-induced antigen retrieval in citrate buffer (Muto Pure Chemicals Co., Ltd, Tokyo, Japan). After washing with PBS, endogenous peroxidase was blocked with $3 \%$ hydrogen peroxide solution in methanol for 15 minutes (Junsei Chemical Co.Ltd, Tokyo, Japan). The tissues were then washed with PBS and were incubated with $5 \%$ bovine serum albumin (BSA) (Sigma Aldrich Chemical Co., St. Louis, Missouri, United States) for 30 minutes to block nonspecific antibody binding. The slides were then incubated overnight at $4^{\circ} \mathrm{C}$ with monoclonal antibodies against HMGB1 (Sigma Aldrich Chemical Co., St. Louis, Missouri, United States) at a dilution of 1:300. After washing three times with PBS, and incubation with biotinylated rabbit antimouse immunoglobulin-labeled globulin (Nichirei, Tokyo, Japan) for 20 minutes, Meyer's hematoxylin (Sigma Aldrich Chemical Co., St. Louis, Missouri, United States) was used for counterstaining. One field per specimen, from an optimally stained area at a magnification of $\times 400$, was randomly selected for evaluation. HMGB1 expression was strongly and predominantly detected in the nuclei of cancer cells, and it was also weakly observed in the cytoplasm of a few cases (Figure 1). Specimens were classified into high or low HMGB1 expression groups, according to their expression in residual cancer cells. When diffuse HMGB1 staining in the nuclei of residual cancer cells was observed, it was considered as high HMGB1 expression (Figure 1a), and when staining was only observed focally, it was considered as low expression (Figure 1b). Staining was evaluated independently by two observers trained in pathology ( $\mathrm{KH}$ and $\mathrm{SK}$ ) who were unaware of the clinical findings. Discrepancies between their findings were resolved by discussion. The correlations between HMGB1 expression and clinicopathological features, tumor recurrence-free survival, and overall survival rates were analyzed.

\section{Statistical analysis}

The statistical significance of differences was evaluated using non-paired Student's t-test, as appropriate. An


Figure 1 HMGB1 Immunohistochemical staining of lower rectal carcinoma treated with chemoradiotherapy. (a) High HMGB1 expression (original magnification, $\times 200$ ). HMGB1 is predominant in the nuclei of tumor cells, and shows diffuse and strong expression. (b) Tumors with low HMGB1 expression (original magnification, $\times 200$ ). HMGB1 expression is observed in focal tumor cells.

association was considered significant when the exact significance level of the test was less than 0.05. Actuarial overall survival and recurrence-free rates were analyzed using the Kaplan-Meier method. The significance of several variables of the tumor regression grade after CRT was analyzed using logistic regression analysis in multivariate analysis.

\section{Results}

\section{Patients' characteristics}

The clinicopathological findings of the 75 patients with lower rectal cancer who had received preoperative CRT and undergone surgical resection are listed in Table 2. A total of 45 patients $(60.0 \%)$ were male, and 30 (40.0\%) were female, with an age range of 33 to 79 years (mean $61.4 \pm 10.2$ years). There were $23(30.7 \%)$ patients with stage 1 lower rectal cancer, 32 (42.7\%) with stage 2, 13 (17.4\%) with stage 3 , and 7 (9.3\%) with stage 4. According 
Table 2 Characteristics of rectal cancer patients in this study

\begin{tabular}{|c|c|c|}
\hline \multicolumn{3}{|l|}{ Characteristics } \\
\hline Age: mean age (years) $\pm S D$ & & $61.4 \pm 10.2$ \\
\hline \multirow[t]{2}{*}{ Gender } & M & $45(60.0 \%)$ \\
\hline & $\mathrm{F}$ & $30(40.0 \%)$ \\
\hline Tumor size $(\mathrm{mm}) \pm \mathrm{SE}$ & & $45.4 \pm 8.6$ \\
\hline \multirow[t]{4}{*}{ Depth of tumor* } & $\mathrm{T} 1$ & $7(9.3 \%)$ \\
\hline & $\mathrm{T} 2$ & $21(28.0 \%)$ \\
\hline & $\mathrm{T} 3$ & $42(56.0 \%)$ \\
\hline & $\mathrm{T} 4$ & $5(6.7 \%)$ \\
\hline \multirow[t]{4}{*}{ Histologic type $e^{* *}$} & Well & 49 (65.3\%) \\
\hline & Moderate & $24(32.0 \%)$ \\
\hline & Poor & $0(0 \%)$ \\
\hline & Mucinous & $2(2.7 \%)$ \\
\hline \multirow[t]{2}{*}{ Lymphatic invasion } & Positive & $7(9.3 \%)$ \\
\hline & Negative & $68(90.7 \%)$ \\
\hline \multirow[t]{2}{*}{ Venous invasion } & Positive & $39(52.0 \%)$ \\
\hline & Negative & $36(48.0 \%)$ \\
\hline \multirow[t]{2}{*}{ Lymph node metastasis } & Positive & $15(20.0 \%)$ \\
\hline & Negative & $60(80.0 \%)$ \\
\hline \multirow[t]{2}{*}{ Distant metastasis } & Positive & $2(1.3 \%)$ \\
\hline & Negative & $152(98.7 \%)$ \\
\hline \multirow[t]{2}{*}{ Liver metastasis } & Positive & $1(0.6 \%)$ \\
\hline & Negative & $153(99.4 \%)$ \\
\hline \multirow[t]{4}{*}{ Stage* } & 1 & $23(30.7 \%)$ \\
\hline & 2 & $32(42.7 \%)$ \\
\hline & 3 & $13(17.4 \%)$ \\
\hline & 4 & $7(9.3 \%)$ \\
\hline \multirow[t]{2}{*}{ Tumor regression grade } & 1 & $46(61.3 \%)$ \\
\hline & 2 & $29(38.7 \%)$ \\
\hline Reduction ratio $(\%) \pm S D$ & & $33.0 \pm 16.1$ \\
\hline
\end{tabular}

${ }^{*}$ TNM Classification of Malignant Tumors, seventh edition. ${ }^{* *}$ World Health Organization (WHO) histological criteria.

to the tumor regression grade, $46(61.3 \%)$ were grade 1 and $29(38.7 \%)$ were grade 2 . The average reduction ratio after CRT was $33.0 \pm 16.1 \%$.

\section{Correlation between clinicopathological features and HMGB1 expression in rectal cancer patients treated with chemoradiotherapy}

The correlation between HMGB1 expression and the clinicopathological characteristics of tumors is shown in Table 3. A total of 52 (69.3\%) patients had high HMGB1 expression, and 23 (30.7\%) had low expression. No correlation was found between HMGB1 expression and age, gender, tumor size, depth of tumor, lymph node metastasis, and TNM stage. However, HMGB1 expression significantly correlated with the histological type of the tumor $(P=0.02)$, lymphatic invasion $(P=0.02)$, and venous invasion $(P=$ $0.05)$. Well-differentiated tumors were observed in $87 \%$ (20 out of 23) of tumors with low HMGB1 expression and $55.8 \%$ (29 out of 52$)$ of tumors with high expression $(P=$ 0.02 ). Lymphatic invasion was identified in $13.5 \%$ (seven out of 52) of tumors with high HMGB1 expression, but in no cases with low HMGB1 $(P=0.02)$. Venous invasion was present in 59.6\% (31 out of 52) of tumors with high HMGB1 expression compared to $34.8 \%$ (eight out of 23) of those with low expression $(P=0.05)$. Moreover, compared to low expression, high HMGB1 expression was associated with a poorer response to CRT, in terms of both the tumor reduction ratio $(42.2$ versus $28.9 \%$, respectively; $P<0.01)$ and the post-CRT histological tumor regression grade (43.5 versus $69.2 \%$ and 56.5 versus $30.8 \%$, respectively for grades 1 and 2 ; $P=0.03)$.

\section{Recurrence-free survival and overall survival analysis of} rectal cancer patients in relation to HMGB1 expression

Using Kaplan-Meier analysis, the log-rank test revealed no significant correlation between the expression of HMGB1 and recurrence-free survival, overall survival (Figure 2a, b), and local recurrence (data not shown).

\section{Discussion}

HMGB1 is both a nuclear factor and a secreted protein that acts as a damage-associated molecular pattern molecule (DAMP) [40]. Recently, HMGB1 has been shown to play an important role in cancer biology, including angiogenesis, apoptosis, growth signals, tissue invasion, and metastasis [41-43]. In this study, we focused on the HMGB1 staining pattern in the nuclear compartment, but not the cytoplasm, of rectal cancer cells, and evaluated its possible role in tumor progression and resistance to treatment.

In our series, HMGB1 expression significantly correlated with the histological type of tumor, lymphatic invasion, and venous invasion in rectal cancer. Patients with high HMGB1 expression were more resistant to CRT, as revealed by lower tumor reduction ratio and lower postCRT histological tumor regression grade. This may imply that rectal cancers with high HMGB1 expression have higher malignancy potential, acquiring resistance to CRT. Corroborating these findings, we observed that HMGB1 expression significantly correlated with lymphatic and venous invasion. In oral cancer, HMGB1 has been reported to promote lymphangiogenesis through the upregulation of vascular endothelial growth factor C (VEGF-C) and vascular endothelial growth factor D (VEGF-D) [44], which might be linked to the transmigration of HMGB1 [27]. Furthermore, in nasopharyngeal carcinoma cells, endogenous HMGB1 expression was associated with invasiveness [41]. 
Table 3 Correlation between the clinicopathologic features and HMGB1 expression

\begin{tabular}{|c|c|c|c|c|}
\hline \multirow[t]{2}{*}{ Characteristics } & & \multirow{2}{*}{$\begin{array}{l}\text { HMGB1 } \\
\text { High expression }\end{array}$} & \multirow{2}{*}{$\begin{array}{l}\text { HMGB1 } \\
\text { Low expression }\end{array}$} & \multirow[t]{2}{*}{$P$ value } \\
\hline & & & & \\
\hline & & $52(69.3 \%)$ & $23(30.7 \%)$ & \\
\hline Age: mean \pm SD (years) & & $61.6 \pm 10.3$ & $61.1 \pm 10.2$ & 0.87 \\
\hline \multirow[t]{2}{*}{ Gender } & M & $30(57.7 \%)$ & $15(65.2 \%)$ & 0.54 \\
\hline & $\mathrm{F}$ & $22(42.3 \%)$ & $8(34.8 \%)$ & \\
\hline Tumor size $(\mathrm{mm}) \pm \mathrm{SE}$ & & $5.35 \pm 1.02$ & $2.72 \pm 1.53$ & 0.16 \\
\hline \multirow[t]{4}{*}{ Depth of tumor* } & $\mathrm{T} 1$ & $5(9.6 \%)$ & $2(8.7 \%)$ & 0.55 \\
\hline & $\mathrm{T} 2$ & $12(23.1 \%)$ & $9(39.1 \%)$ & \\
\hline & T3 & $31(59.6 \%)$ & $11(47.8 \%)$ & \\
\hline & $\mathrm{T} 4$ & $4(7.7 \%)$ & $1(4.4 \%)$ & \\
\hline \multirow[t]{2}{*}{ Lymph node metastasis } & Positive & $13(25.0 \%)$ & $2(8.7 \%)$ & 0.08 \\
\hline & Negative & $39(75.0 \%)$ & $21(91.3 \%)$ & \\
\hline \multirow[t]{3}{*}{ Histologic type ${ }^{* *}$} & Well & $29(55.8 \%)$ & $20(87.0 \%)$ & 0.02 \\
\hline & Moderate & $21(40.4 \%)$ & $3(13.0 \%)$ & \\
\hline & Mucinous & $2(3.9 \%)$ & $0(0 \%)$ & \\
\hline \multirow[t]{2}{*}{ Lymphatic invasion } & Positive & $7(13.5 \%)$ & $0(0 \%)$ & 0.02 \\
\hline & Negative & $45(86.5 \%)$ & $23(100 \%)$ & \\
\hline \multirow[t]{2}{*}{ Venous invasion } & Positive & $31(59.6 \%)$ & $8(34.8 \%)$ & 0.05 \\
\hline & Negative & $21(40.4 \%)$ & $15(65.2 \%)$ & \\
\hline \multirow[t]{2}{*}{ Tumor regression grade } & 1 & $36(69.2 \%)$ & $10(43.5 \%)$ & 0.03 \\
\hline & 2 & $16(30.8 \%)$ & $13(56.5 \%)$ & \\
\hline Reduction ratio $(\%) \pm S D$ & & $28.9 \pm 2.1$ & $42.2 \pm 3.1$ & 0 \\
\hline \multirow[t]{4}{*}{ Stage ${ }^{* *}$} & 1 & 14 (26.9\%) & 9 (39.1\%) & 0.22 \\
\hline & 2 & $21(40.4 \%)$ & $11(47.8 \%)$ & \\
\hline & 3 & 11 (21.1\%) & $2(8.7 \%)$ & \\
\hline & 4 & $6(11.5 \%)$ & 1 (4.4\%) & \\
\hline
\end{tabular}

a

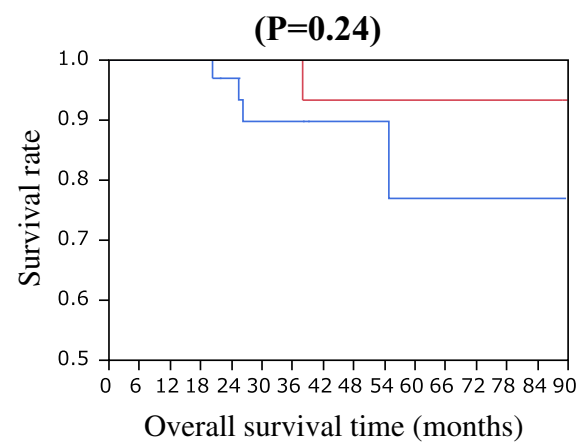

b Disease free survival

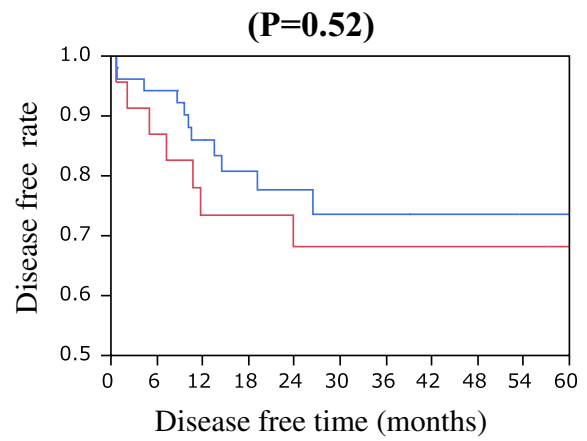

HMGB-1(low expression)

Figure 2 Recurrence-free survival and overall survival analysis of colon cancer patients in relation to HMGB-1 expression. (a) Overall survival rates. (b) Kaplan-Meier plot showing disease-free survival rates of rectal cancer patients receiving preoperative chemoradiotherapy. 
Possible mechanisms of induction of resistance to radiotherapy and chemotherapy by HMGB1 may be: 1 ) the facilitation of protein-protein interaction and recognition of DNA damage in the process of mismatch repair [45]; 2) regulation of autophagy [31]; and 3) regulation of heat shock protein beta-1 (HSPB1) gene expression, which regulates mitophagy [46]. After DNA damage induced by ultraviolet light irradiation or platination, HMGB1 is sequestered in the nucleus, which is classically associated with apoptosis [8]. An increased level of HMGB1 might promote DNA repair induced by radiation. In addition, HMGB1 is a critical regulator of autophagy [31], promoting drug resistance in osteosarcoma [32] and leukemia cells [47]. Chemotherapy-induced HMGB1 expression in osteosarcoma cells promoted autophagy through controlling the formation of the Beclin 1-phosphatidylinositol 3-kinase class 3 (PI3KC3) complex to inhibit apoptosis and increase drug resistance [32]. Most cancer therapies, such as radiation and anticancer drugs, induce cancer cells to undergo autophagy $[48,49]$, which is an important mechanism of resistance to therapy; thus, mechanisms involving HMGB1 might be key regulators of resistance to anti-cancer therapies. Furthermore, nuclear HMGB1 regulates HSPB1 gene expression. Mitophagy is responsible for the elimination of dysfunctional and impaired mitochondria. It is unclear whether or how mitophagy triggered by dysfunctional mitochondria is regulated by nuclear mediators. However, it has been recognized that HMGB1 modulates mitochondrial respiration and morphological features by helping to sustain autophagy in mitochondrial maintenance through regulation of HSPB1 gene expression [46]. Autophagy and mitophagy, therefore, are involved in sustaining mitochondrial respiration and morphological features after cellular stress and mitochondrial injury. These mechanisms of nuclear HMGB1, including DNA repair, and regulation of autophagy and mitophagy, might be involved in the development of resistance of rectal cancer cells to CRT. Thus, targeting of HMGB1 may be a promising approach for the development of novel therapeutic strategies for rectal cancer.

In our series, however, no significant correlation between HMGB1 expression and recurrence-free or overall survival was found. Since HMGB1 is reported to have paradoxical effects on tumor progression by affecting both the cancer cells and the tumor immunity, the counter-balance between these two effects may be important in determining the final effect. However, caution is required in interpreting our present data. HMGB1 could not be identified as an effective predictive factor for CRT, because only tumor tissues obtained after CRT were used for immunohistochemical staining of HMGB1, and immunostaining of HMGB1 may be affected by CRT itself. Another limitation was the small number of patients, and the retrospective nature of the study.

\section{Conclusions}

In conclusion, using immunohistochemistry, this study demonstrated the association of HMGB1 expression in human rectal cancer tissue exposed to CRT with tumor invasiveness and resistance to therapy. HMGB1, which regulates both cell death and cell survival, likely plays a role in the development of carcinogenesis and chemoresistance. Further large-scale prospective studies with longterm follow-up periods, evaluating samples obtained preand post-CRT, are needed to determine the potential role of HMGB1 as a prognostic factor for CRT in rectal cancer.

\section{Abbreviations}

CRT: Chemoradiotherapy; HMGB1: High-mobility group box 1; HSPB1: Heat shock protein beta-1; RAGE: Receptors such as advanced glycation end-products; TLR-2: Toll-like receptor 2; TLR-4: Toll-like receptor 4; DAMP: damage associated molecular pattern molecule; VEGF-C: vascular endothelial growth factor $C$; VEGF-D: vascular endothelial growth factor D; HSPB1: heat shock protein beta-1; PI3KC3: phosphatidylinositol 3-kinase class 3.

\section{Competing interests}

The authors declare that they have no competing interests related to this manuscript.

\section{Authors' contributions}

All authors read and approved the final manuscript.

\section{Acknowledgements}

We would like to thank Editage (www.editage.jp) for English language editing.

\section{Author details}

'Department of Surgical Oncology, Graduate School of Medicine, The University of Tokyo, 7-3-1 Hongo, Bunkyo-ku, Tokyo 113-8655, Japan. 2Department of Transfusion Medicine, Graduate School of Medicine, The University of Tokyo, 7-3-1 Hongo, Bunkyo-ku, Tokyo 113-8655, Japan.

Received: 30 August 2014 Accepted: 18 November 2014 Published: 27 January 2015

\section{References}

1. Czura CJ, Wang H, Tracey KJ. Dual roles for HMGB1: DNA binding and cytokine. J Endotoxin Res. 2001;7:315-21.

2. Lotze MT, Tracey KJ. High-mobility group box 1 protein (HMGB1): nuclear weapon in the immune arsenal. Nat Rev Immunol. 2005;5:331-42.

3. Muller S, Scaffidi P, Degryse B, Bonaldi T, Ronfani L, Agresti A, et al. New EMBO members' review: the double life of HMGB1 chromatin protein: architectural factor and extracellular signal. EMBO J. 2001;20:4337-40.

4. Dong Xda E, Ito N, Lotze MT, Demarco RA, Popovic P, Shand SH, et al. High mobility group box I (HMGB1) release from tumor cells after treatment: implications for development of targeted chemoimmunotherapy. J Immunother. 2007;30:596-606.

5. Ellerman JE, Brown CK, de Vera M, Zeh HJ, Billiar T, Rubartelli A, et al. Masquerader: high mobility group box-1 and cancer. Clin Cancer Res. 2007;13:2836-48

6. Tang D, Kang R, Zeh 3rd HJ, Lotze MT. High-mobility group box 1 and cancer. Biochim Biophys Acta. 2010;1799:131-40.

7. Erlandsson Harris $\mathrm{H}$, Andersson U. Mini-review: The nuclear protein HMGB as a proinflammatory mediator. Eur J Immunol. 2004;34:1503-12.

8. Scaffidi P, Misteli T, Bianchi ME. Release of chromatin protein HMGB1 by necrotic cells triggers inflammation. Nature. 2002;418:191-5. 
9. Fiuza C, Bustin M, Talwar S, Tropea M, Gerstenberger E, Shelhamer JH, et al. Inflammation-promoting activity of HMGB1 on human microvascular endothelial cells. Blood. 2003;101:2652-60

10. Yang H, Ochani M, Li J, Qiang X, Tanovic M, Harris HE, et al. Reversing established sepsis with antagonists of endogenous high-mobility group box 1. Proc Natl Acad Sci U S A. 2004;101:296-301.

11. Park JS, Gamboni-Robertson F, He Q, Svetkauskaite D, Kim JY, Strassheim D et al. High mobility group box 1 protein interacts with multiple Toll-like receptors. Am J Physiol Cell Physiol. 2006;290:C917-24.

12. Rovere-Querini $P$, Capobianco A, Scaffidi $P$, Valentinis B, Catalanotti F, Giazzon M, et al. HMGB1 is an endogenous immune adjuvant released by necrotic cells. EMBO Rep. 2004;5:825-30.

13. Wang $H$, Yang $H$, Tracey $K J$. Extracellular role of HMGB1 in inflammation and sepsis. J Intern Med. 2004;255:320-31.

14. Tsung A, Sahai R, Tanaka H, Nakao A, Fink MP, Lotze MT, et al. The nuclear factor HMGB1 mediates hepatic injury after murine liver ischemia-reperfusion. Journal Exp Med. 2005:201:1135-43.

15. Tang D, Kang R, Cao L, Zhang G, Yu Y, Xiao W, et al. A pilot study to detect high mobility group box 1 and heat shock protein 72 in cerebrospinal fluid of pediatric patients with meningitis. Crit Care Med. 2008;36:291-5.

16. Qi ML, Tagawa K, Enokido Y, Yoshimura N, Wada Y, Watase K, et al. Proteome analysis of soluble nuclear proteins reveals that HMGB1/2 suppress genotoxic stress in polyglutamine diseases. Nat Cell Biol. 2007:9:402-14

17. Enokido $\mathrm{Y}$, Yoshitake A, Ito H, Okazawa H. Age-dependent change of HMGB1 and DNA double-strand break accumulation in mouse brain. Biochem Biophys Res Commun. 2008;376:128-33.

18. Sparvero $L$, Asafu-Adjei D, Kang R, Tang D, Amin N, Im J, et al. RAGE (Receptor for Advanced Glycation Endproducts), RAGE ligands, and their role in cancer and inflammation. J Transl Med. 2009;7:17.

19. Palumbo R, Sampaolesi M, De Marchis F, Tonlorenzi R, Colombetti S, Mondino A, et al. Extracellular HMGB1, a signal of tissue damage, induces mesoangioblast migration and proliferation. J Cell Biol. 2004;164:441-9.

20. Wang $\mathrm{H}$, Bloom O, Zhang M, Vishnubhakat JM, Ombrellino M, Che J, et al. HMG-1 as a late mediator of endotoxin lethality in mice. Science. 1999:285:248-51.

21. Yu W, Kim J, Ossowski L. Reduction in surface urokinase receptor forces malignant cells into a protracted state of dormancy. J Cell Biol. 1997;137:767-77

22. Taguchi A, Blood DC, del Toro G, Canet A, Lee DC, Qu W, et al. Blockade of RAGE-amphoterin signalling suppresses tumour growth and metastases. Nature. 2000;405:354-60

23. Ishiguro H, Nakaigawa N, Miyoshi Y, Fujinami K, Kubota Y, Uemura H. Receptor for advanced glycation end products (RAGE) and its ligand amphoterin are overexpressed and associated with prostate cancer development. Prostate. 2005;64:92-100.

24. Volp K, Brezniceanu ML, Bosser S, Brabletz T, Kirchner T, Gottel D, et al. Increased expression of high mobility group box 1 (HMGB1) is associated with an elevated level of the antiapoptotic c-IAP2 protein in human colon carcinomas. Gut. 2006;55:234-42.

25. Choi YR, Kim H, Kang HJ, Kim NG, Kim JJ, Park KS, et al. Overexpression of high mobility group box 1 in gastrointestinal stromal tumors with KIT mutation. Cancer Res. 2003:63:2188-93.

26. Yao X, Zhao G, Yang H, Hong X, Bie L, Liu G. Overexpression of high-mobility group box 1 correlates with tumor progression and poor prognosis in human colorectal carcinoma. J Cancer Res Clin Oncol. 2010;136:677-84.

27. Moriwaka Y, Luo Y, Ohmori H, Fujii K, Tatsumoto N, Sasahira T, et al. HMGB1 attenuates anti-metastatic defense of the lymph nodes in colorectal cancer. Pathobiology. 2010;77:17-23

28. Yang $\mathrm{H}$, Wang $\mathrm{H}$, Czura CJ, Tracey KJ. The cytokine activity of HMGB1. J Leukoc Biol. 2005;78:1-8

29. Huttunen $\mathrm{HJ}$, Fages $\mathrm{C}$, Rauvala $\mathrm{H}$. Receptor for advanced glycation end products (RAGE)-mediated neurite outgrowth and activation of NF-kappaB require the cytoplasmic domain of the receptor but different downstream signaling pathways. J Biol Chem. 1999;274:19919-24.

30. Bartling B, Hofmann HS, Weigle B, Silber RE, Simm A. Down-regulation of the receptor for advanced glycation end-products (RAGE) supports non-small cell lung carcinoma. Carcinogenesis. 2005;26:293-301.

31. Tang D, Kang R, Cheh CW, Livesey KM, Liang X, Schapiro NE, et al. HMGB1 release and redox regulates autophagy and apoptosis in cancer cells. Oncogene. 2010;29:5299-310.
32. Huang J, Ni J, Liu K, Yu Y, Xie M, Kang R, et al. HMGB1 promotes drug resistance in osteosarcoma. Cancer Res. 2012;72:230-8.

33. Apetoh L, Ghiringhelli F, Tesniere A, Obeid M, Ortiz C, Criollo A, et al. Toll-like receptor 4-dependent contribution of the immune system to anticancer chemotherapy and radiotherapy. Nat Med. 2007;13:1050-9.

34. Curtin JF, Liu N, Candolfi M, Xiong W, Assi H, Yagiz K, et al. HMGB1 mediates endogenous TLR2 activation and brain tumor regression. PLoS Med. 2009;6:e10

35. Weitz J, Koch M, Debus J, Hohler T, Galle PR, Buchler MW. Colorectal cancer. Lancet. 2005;365:153-65.

36. Belluco C, De Paoli A, Canzonieri V, Sigon R, Fornasarig M, Buonadonna A, et al. Long-term outcome of patients with complete pathologic response after neoadjuvant chemoradiation for CT3 rectal cancer: implications for local excision surgical strategies. Ann Surg Oncol. 2011;18:3686-93.

37. Sobin LH, Gospodarowicz MK, Wittekind C. TNM Classification of Malignant Tumors. .7th edition. Hoboken, NJ, United States: Wiley-Blackwell; 2009.

38. Organnization WH. International Classification of Diseases for Oncology. 3rd ed. International Association of Cancer Registries: Lyon, France; 2000.

39. Rectum JS, Cot C. General Rules for Clinical and Pathological Studies on Cancer of the Colon, Rectum, and Anus. Tokyo, Japan: Kanehara \& Co; 2006.

40. Bianchi ME. DAMPs, PAMPs and alarmins: all we need to know about danger. J Leukoc Biol. 2007;81:1-5.

41. Mantovani A. Cancer: inflaming metastasis. Nature. 2009;457:36-7.

42. Mantovani A, Allavena P, Sica A, Balkwill F. Cancer-related inflammation. Nature. 2008;454:436-44

43. Vakkila J, Lotze MT. Inflammation and necrosis promote tumour growth. Nat Rev Immunol. 2004;4:641-8.

44. Sasahira T, Kirita T, Oue N, Bhawal UK, Yamamoto K, Fujii K, et al. High mobility group box-1-inducible melanoma inhibitory activity is associated with nodal metastasis and lymphangiogenesis in oral squamous cell carcinoma. Cancer Sci. 2008:99:1806-12.

45. Yuan F, Gu L, Guo S, Wang C, Li GM. Evidence for involvement of HMGB1 protein in human DNA mismatch repair. J Biol Chem. 2004:279:20935-40.

46. Tang D, Kang R, Livesey KM, Kroemer G, Billiar TR, Van Houten B, et al. High-mobility group box 1 is essential for mitochondrial quality control. Cell Metab. 2011;13:701-11.

47. Liu L, Yang M, Kang R, Wang Z, Zhao Y, Yu Y, et al. HMGB1-induced autophagy promotes chemotherapy resistance in leukemia cells. Leukemia. 2011;25:23-31.

48. Apel A, Herr I, Schwarz H, Rodemann HP, Mayer A. Blocked autophagy sensitizes resistant carcinoma cells to radiation therapy. Cancer Res. 2008:68:1485-94

49. Levine B. Cell biology: autophagy and cancer. Nature. 2007;446:745-7.

doi:10.1186/1477-7819-13-7

Cite this article as: Hongo et al:: Immunohistochemical detection of high-mobility group box 1 correlates with resistance of preoperative chemoradiotherapy for lower rectal cancer: a retrospective study. World Journal of Surgical Oncology 2015 13:7.

\section{Submit your next manuscript to BioMed Central and take full advantage of:}

- Convenient online submission

- Thorough peer review

- No space constraints or color figure charges

- Immediate publication on acceptance

- Inclusion in PubMed, CAS, Scopus and Google Scholar

- Research which is freely available for redistribution 